\title{
About the operational determination of the state and parameters of flowing moist air
}

\author{
Magda Vestfálová1,*, and Pavel Šafařík ${ }^{2}$ \\ ${ }^{1}$ KEZ, TU Liberec, Studentská 1402/2, 46117 Liberec 1, Czech Republic \\ ${ }^{2} \mathrm{CTU}$ in Prague, FME, Department of Fluid Dynamics and Thermodynamics, Technická 4, 16607 Praha 6, Czech Republic
}

\begin{abstract}
The presented paper deals with the solution of moist air parameters for the needs of aerodynamic research or design. From the thermodynamic theory of moist air, a p-t diagram of moist air is designed to allow the operative expression of the process and state of the moist air. Using this diagram, it is possible to illustratively describe the course of parameters at various state changes in moist air such as isentropic expansion and compression, isothermal expansion and compression, isobaric state change, isochoric state change, or general polytrophic state change. The initial state of moist air is determined by the pressure, temperature and moisture of the air. In the $\mathrm{p}$-t diagram, the process is expressed by the applicable curve; the identification of the parameters in which the phase transformation occurs in moist air is significant. Uncertainty analysis is performed.
\end{abstract}

\section{Introduction}

For quick determination of state of moist air, a Mollier's diagram of moist air is commonly used, it is a diagram that has a specific moisture of moist air on one axis (oriented from the vertical direction by $135^{\circ}$ ) and moist air enthalpy on the other axis (vertical). However, since the condition of moist air is determined by three parameters, one of the parameters (moist air pressure) must be fixed in the Mollier's diagram - that means, Mollier's moist air diagram is always designed for one concrete value of total pressure. In determining the condition of atmospheric moist air (when the pressure is always about $100 \mathrm{kPa}$ ), no problems occur. However, if it is necessary to solve changes of moist air that occur at other than atmospheric pressure, it should be noted that in the Mollier's diagram constructed for a different pressure value, all curves of constant relative moisture (and hence the saturation curve too) will be shifted. If it is necessary to solve such changes of moist air in which pressure changes, the Mollier's diagram is absolutely unusable. The aim of this paper is to construct such a diagram of moist air in which it would be possible to search the properties of moist air corresponding to different temperatures, moisture, but also to various pressures.

\section{Fundamentals of moist air thermo- dynamics}

Moist air is a mixture of dry air and water. The moisture (water) contained in the moist air is always in the form of steam, but in addition (in the case of a heterogeneous mixture), part of the moisture in moist air may also be in a liquid or solid state. [1]

The moist air temperature $t_{M A}\left[{ }^{\circ} \mathrm{C}\right]$ is equal to the temperature of its components

$$
t_{M A}=t_{D A}=t_{V}=t \text {. }
$$

The moist air pressure $p_{M A}[\mathrm{~Pa}]$ is, according to Dalton's law, equal the sum of the partial pressures of dry air and water vapor

$$
p_{M A}=p_{D A}+p_{V} .
$$

The saturated water vapor pressure $p_{v}^{\prime \prime}[\mathrm{Pa}]$ is a significant variable for moist air, determining the moisture content limit in the air for the existence of a homogeneous mixture:

- if $p_{v}<p_{v}^{\prime \prime}$, the moist air is unsaturated and the mixture is homogeneous;

- if $p_{v}=p_{v}^{\prime \prime}$, the moist air is saturated and the mixture is homogeneous.

If there is more moisture in moist air than corresponds to the state of saturated moist air, excreted moisture condenses in liquid or solid form and moist air, as a heterogeneous mixture, is then formed by saturated moist air and by excreted condensate.

Pressure of saturated water vapor is an unambiguous function of temperature

$$
p_{V}^{\prime \prime}=p_{V}^{\prime \prime}(t) \text {. }
$$

For pressure of saturated water vapor, the International Association for Water Vapor Properties has published relationships on temperature for equilibrium between liquid water and steam [2] and between solid phase of water and steam [3].

\footnotetext{
${ }^{*}$ Corresponding author: magda.vestfalova@tul.cz
} 
Absolute air moisture $a\left[\mathrm{~kg} / \mathrm{m}^{3}\right]$ is the mass amount of steam in unit air volume. It is the vapor density $\rho_{v}$ at vapor pressure $p_{v}$ and at temperature $t$. Absolute moisture is defined only for a homogeneous mixture, and can be at a given temperature in the range $\left\langle 0 ; \rho_{v}^{\prime \prime}(t)\right\rangle$.

Relative moisture $\varphi[-]$ is the ratio of absolute air moisture to absolute moisture of the saturated air at a given temperature

$$
\varphi=\frac{a}{a^{\prime \prime}} .
$$

Relative moisture is defined only for a homogeneous mixture, and can be at a given temperature in the range $\langle 0 ; 1\rangle$. Assuming the water vapor contained in the moist air can be described by the ideal gas model, it can be used to calculate the relative moisture the relationship

$$
\varphi=\frac{p_{v}}{p_{v}^{\prime \prime}} .
$$

Specific moisture $x\left[\mathrm{~kg}_{\mathrm{v}} / \mathrm{kg}_{\mathrm{DA}}\right]$ is the ratio of the weight amount of water to the weight amount of dry air

$$
x=\frac{m_{\mathrm{H}_{2} \mathrm{O}}}{m_{D A}} .
$$

In the case of a homogeneous mixture in which moisture is contained only in the form of steam, it is possible to write

$$
x=\frac{m_{V}}{m_{D A}}=\frac{\rho_{V}}{\rho_{D A}} .
$$

If the moist air forms a homogeneous mixture and its components (dry air and steam) can be described by the ideal gas model, it is possible to derive the relationship between specific and relative moisture

$$
x=0.622 \cdot \frac{p_{V}}{p_{M A}-p_{V}} .
$$

resp.

$$
x=0.622 \cdot \frac{\varphi \cdot p_{V}^{\prime \prime}}{p_{M A}-\varphi \cdot p_{V}^{\prime \prime}} .
$$

For the specific moisture of a saturated homogeneous mixture $(\varphi=1)$

$$
x^{\prime \prime}=0.622 \cdot \frac{p_{V}^{\prime \prime}(t)}{p_{M A}-p_{V}^{\prime \prime}(t)}=x^{\prime \prime}(t) .
$$

\section{Curves of saturated moist air in equilibrium $\boldsymbol{p}$ - $\boldsymbol{t}$ diagram}

For a given value of specific moisture of moist air can be calculated for each temperature from equation (10) the pressure of moist air, in which there would be exclude the moisture from the moist air. By plotting this dependence in the equilibrium $p-t$ diagram, we get a curve of saturated moist air (it is a curve $\varphi=1$ ) for given specific moisture. If we plot the dependence of the pressure of saturated moist air on the temperature for different values of the specific moisture (it means with the parameter of the specific moisture $x$ ) in the equilibrium diagram, we obtained the moist air saturation curves (see Figure 1) [4]. In the diagram, the triple point - $t r_{D A}$ and the critical point - $c r_{D A}$ are indicated for dry air. For water vapor, the liquid-vapor saturation curve with the triple point $-t_{V}$ and the critical point $-\mathrm{cr}_{V}$ is indicated. For selected values of specific moisture $x$, the curves of pressure of saturated moist air are plotted.

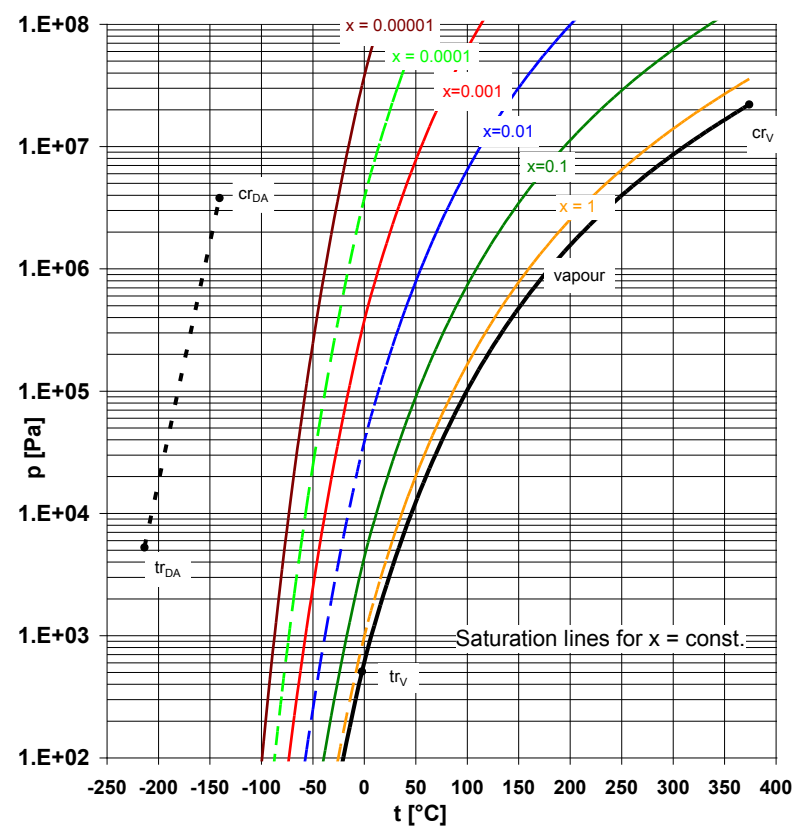

Fig 1. Curves of saturated moist air for different values of specific moisture $x\left[\mathrm{~kg}_{\mathrm{v}} / \mathrm{kg}_{\mathrm{DA}}\right]$ in $p-t$ diagram [4].

Figure 2 [4] is a detail of the $p$ - $t$ diagram, which is a tool for displaying the state of moist air and for determining whether moist air is a homogeneous or heterogeneous mixture.

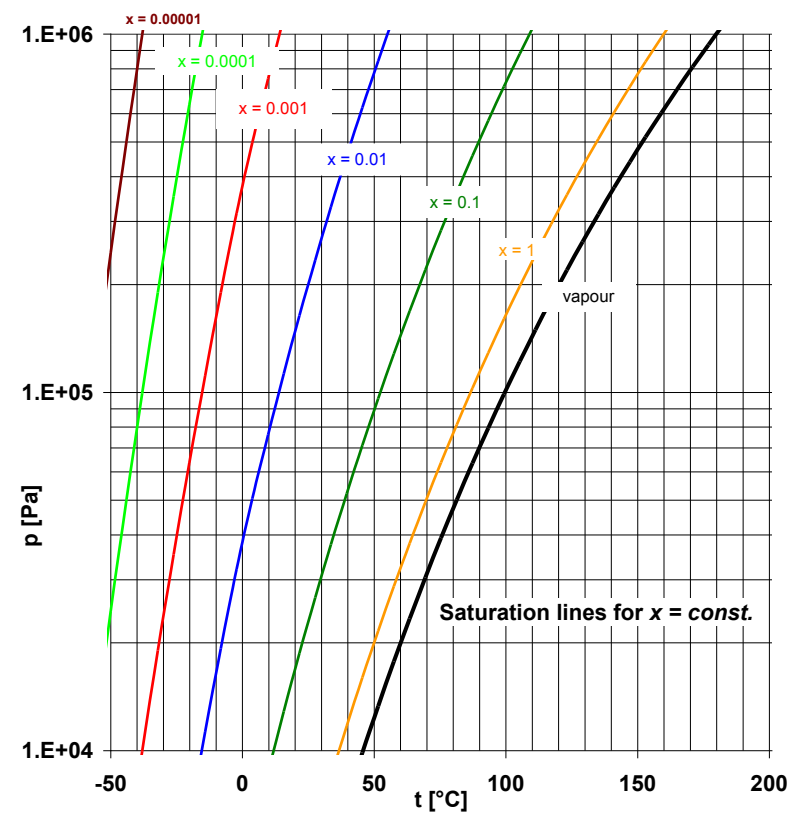

Fig. 2. Curves of saturated moist air for different values of specific moisture $x\left[\mathrm{~kg}_{\mathrm{v}} / \mathrm{kg}_{\mathrm{DA}}\right]$ in $p-t$ diagram (detail) [4]. 


\section{Curves of constant relative moisture in equilibrium $p$ - $t$ diagram}

If we wanted to use the diagram not only to determine the saturation limit, but also to determine the state of unsaturated moist air at different pressures and temperatures, it would be necessary to plot into the equilibrium $p-t$ diagram not only the curves of the dependence of the saturated moist air pressure on the temperature (it is the curves $\varphi=1$ ), but also curves of dependences of moist air pressure on the temperature

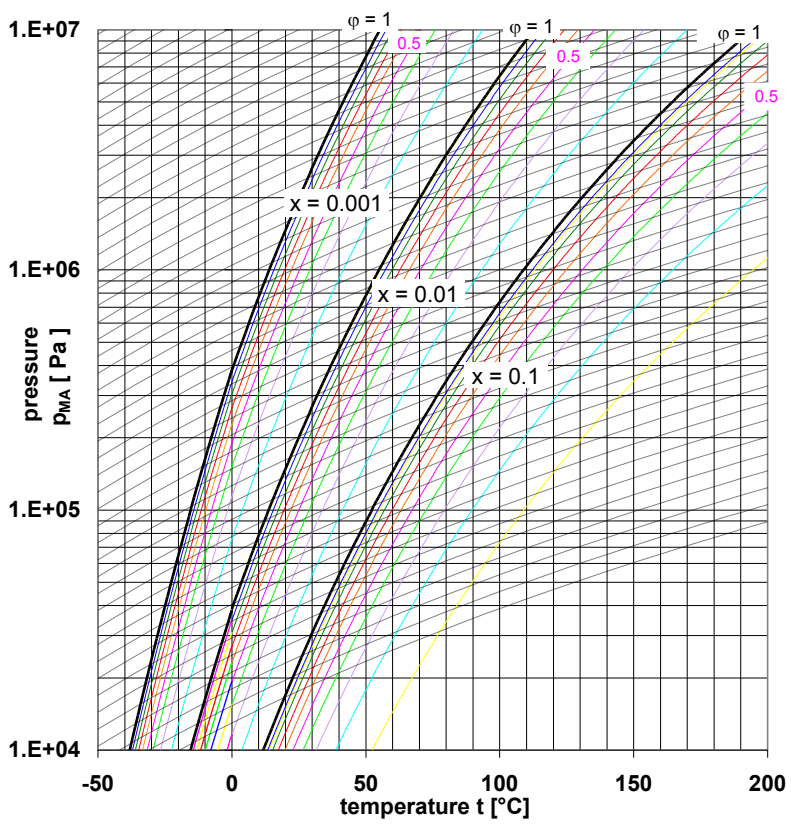

a)

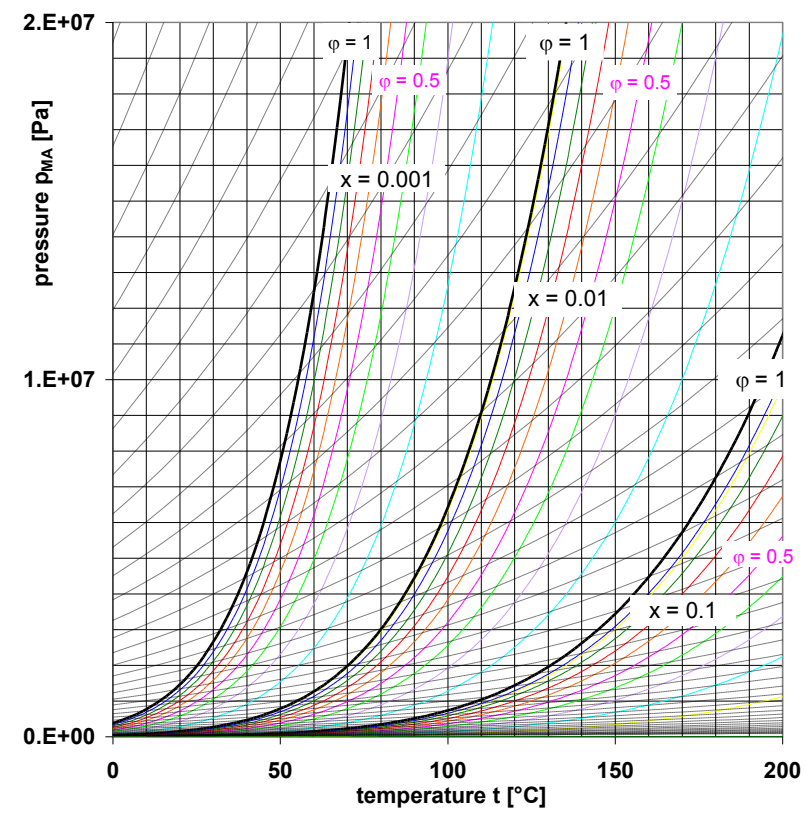

b)

Fig. 3. Curves of constant relative moisture $\varphi=k o n s t$. in the equilibrium $p-t$ diagram for selected values of constant specific moisture $x\left[\mathrm{~kg}_{\mathrm{v}} / \mathrm{kg}_{\mathrm{DA}}\right]$. for other constant relative moisture values $\varphi=k o n s t ~ . ;$ it means the curves

$$
p_{M A}=0.622 \cdot \frac{\varphi}{x} \cdot p_{v}^{\prime \prime}(t)+\varphi \cdot p_{v}^{\prime \prime}(t)
$$

for each (constant) specific moisture value.

This, however, means that for each value of specific moisture $x=$ konst . would be in the diagram several curves corresponding to a constant value of relative moisture $\varphi=k o n s t$. (usually, the displayed curves of constant relative moisture are graded by 0.1 , it is for each constant $x$, it would be further 9 curves) - see Figure 3a, respectively Figure $3 b$.

The diagram would be easy to use for the values of the specific moisture $x$ for which curves are plotted, but for other values of the specific moisture $x$, the estimation of state of moist air from the diagram would be very complicated.

If we, however, in equation (8), respectively (9) neglect partial vapor pressure $p_{v}$ against the total moist air pressure $p_{M A}$, it would be possible to express the total moist air pressure $p_{M A}$ as a function of temperature $t$ (which is uniquely determined by the partial pressure of saturated vapors) and ratio of specific and relative moisture $x / \varphi$ :

$$
p_{M A} \approx 0.622 \cdot \frac{p_{V}^{\prime \prime}(t)}{x / \varphi} .
$$

This dependence could then be plotted in the equilibrium $p-t$ diagram as a set of curves with a parameter - see Figure $4 \mathrm{a}$ respectively Figure 4b.

\section{Use of the equilibrium $p$ - $t$ moist air diagram with curves of a constant ratio of specific and relative moisture}

The method of reading in such a diagram is very simple see detail of $p-t$ diagram - Figure 5:

For moist air, its pressure $p_{M A}$, temperature $t$ and relative moisture $\varphi$ are usually specified. By the pressure and temperature, the point is determined in the equilibrium diagram (for example point $A$ : $\left.p_{M A}=100 \mathrm{kPa}, t=20{ }^{\circ} \mathrm{C}\right)$. In the diagram the point is located on the curve $x / \varphi=0.015$. If relative moisture in state $A$ is for example $\varphi=20 \%$, it means that the specific moisture is $x=0.003 \mathrm{~kg}_{\mathrm{v}} / \mathrm{kg}_{\mathrm{DA}}$. (This value can be quickly verified, for example in a usual Mollier's diagram.)

If there is an isobaric heating, we move in the diagram along the horizontal line $\left(p_{M A}=\right.$ const.$)$ to the desired final temperature (for example to point $B$ : $t=45^{\circ} \mathrm{C}$ ), so we get on the line $x / \varphi=0.06$. Because there is no change in composition, so $x=$ const ., it is possible to calculate the resulting relative moisture $\varphi=5 \%$ (again, it can be easily verified in the Mollier's diagram). 


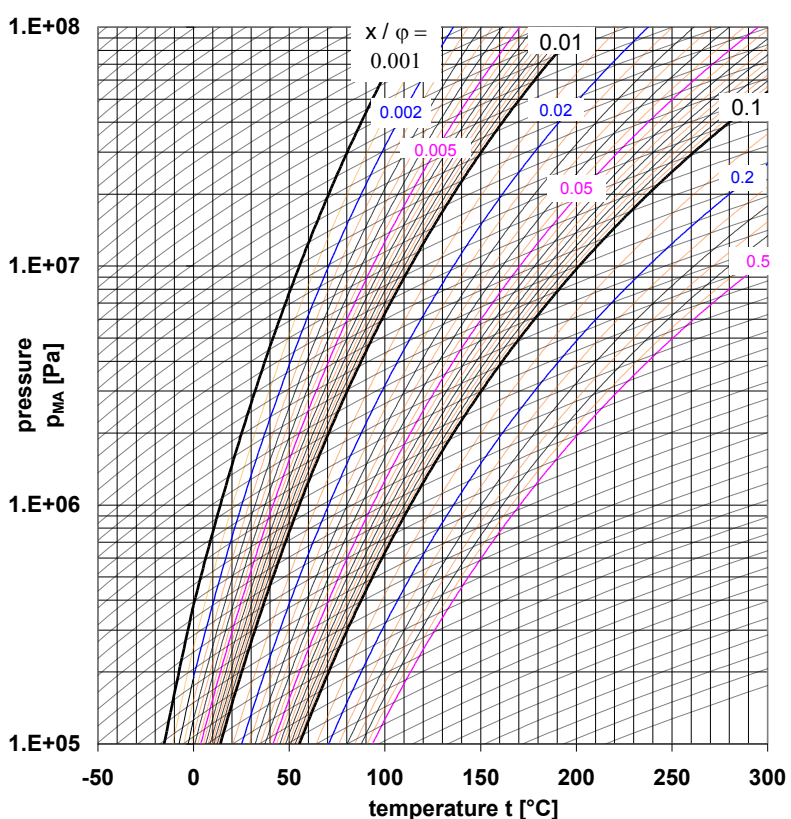

a)

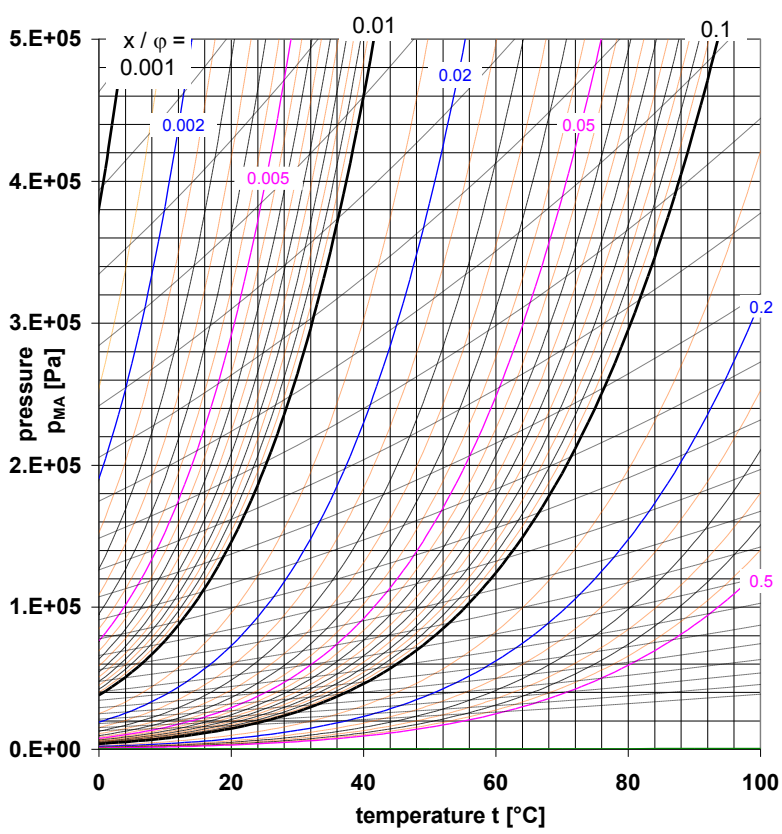

b)

Fig. 4. Curves of constant ratio of specific moisture and relative moisture $x / \varphi$ in the equilibrium $p-t$ moist air diagram.

Similarly, it is possible to solve isothermal changes in the diagram; for example from our initial state $A$, isothermal compression to twice pressure (point $C$ ) means moving to a line $x / \varphi=0.0075$, so, at the same specific moisture is the final relative moisture $\varphi=40 \%$.

In addition, if we plot constant entropy lines in $p-t$ diagram [4], diagram can also be used to solve isentropic changes of the state; for example from a previous state $C$ - isentropic compression to twice pressure (point $D$ : $p_{M A}=400 \mathrm{kPa}$ ) means moving to a line $x / \varphi=0.085$ and so $\varphi=3.5 \%$.

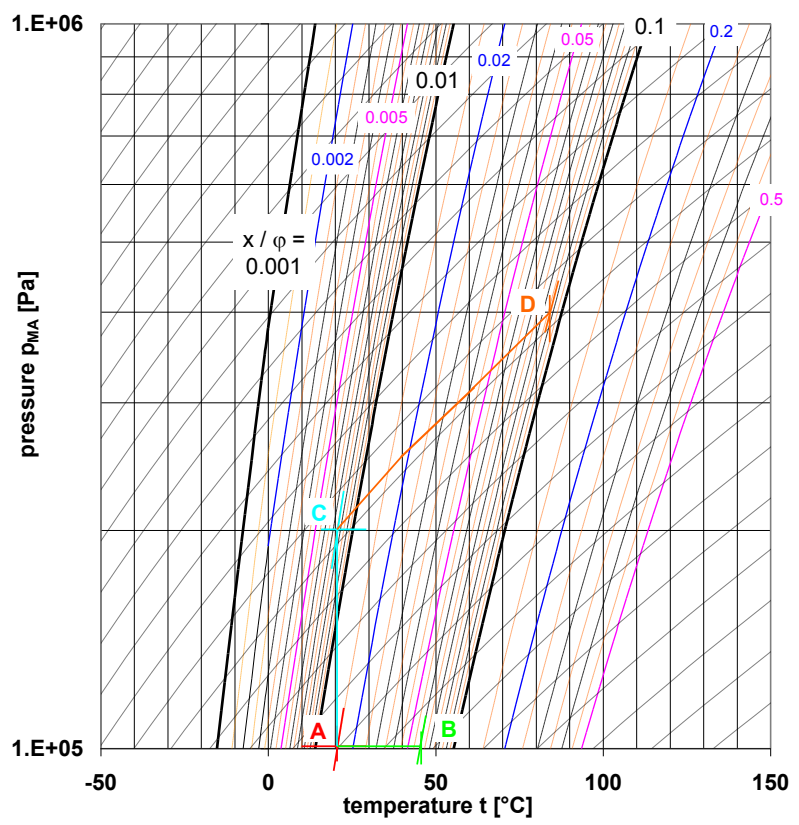

Fig. 5. The method of reading of the properties of moist air in the equilibrium $p-t$ diagram of moist air with curves of constant ratio of specific and relative moisture $x / \varphi$.

\section{Polytrophic change of state of moist air}

The general reversible change of state of ideal gas (polytrophic state change) can be described by the equation [5]

$$
p \cdot v^{n}=\text { const } .,
$$

respectively at pressure -temperature coordinates

$$
p=\text { const } . T^{\frac{n}{n-1}},
$$

where $p[\mathrm{~Pa}]$ is pressure, $v\left[\mathrm{~m}^{3} / \mathrm{kg}\right]$ is specific volume, $T[K]$ is thermodynamic temperature and $n[-]$ is polytrophic exponent, which can theoretically be $\langle-\infty ;+\infty\rangle$. For basic reversible processes, the polytrophic exponent values are:

- $\quad$ isobaric process ( $p=$ const . ): $n=0$;

- $\quad$ isochoric process $(v=$ const . $): n= \pm \infty$;

- $\quad$ isothermal process $(T=$ const . $): n=1$;

- $\quad$ isentropic process $(s=$ const . $): n=\kappa$.

When plotting the equilibrium diagram of moist air at logarithmic coordinates not only for pressure $p[\mathrm{~Pa}]$ but also for temperature $T[\mathrm{~K}]$, each polytrophic process is shown by the line; slope of this line is determined by the polytrophic exponent:

$$
\operatorname{tg}(\alpha)=\frac{n}{n-1},
$$

so for:

- $\quad$ isobaric process: $\alpha=0$;

- $\quad$ isochoric process: $\alpha=\frac{\pi}{4}$; 
- $\quad$ isothermal process: $\alpha=\frac{\pi}{2}$;

- isentropic process: $\alpha=\operatorname{arctg}\left(\frac{\kappa}{\kappa-1}\right)$.

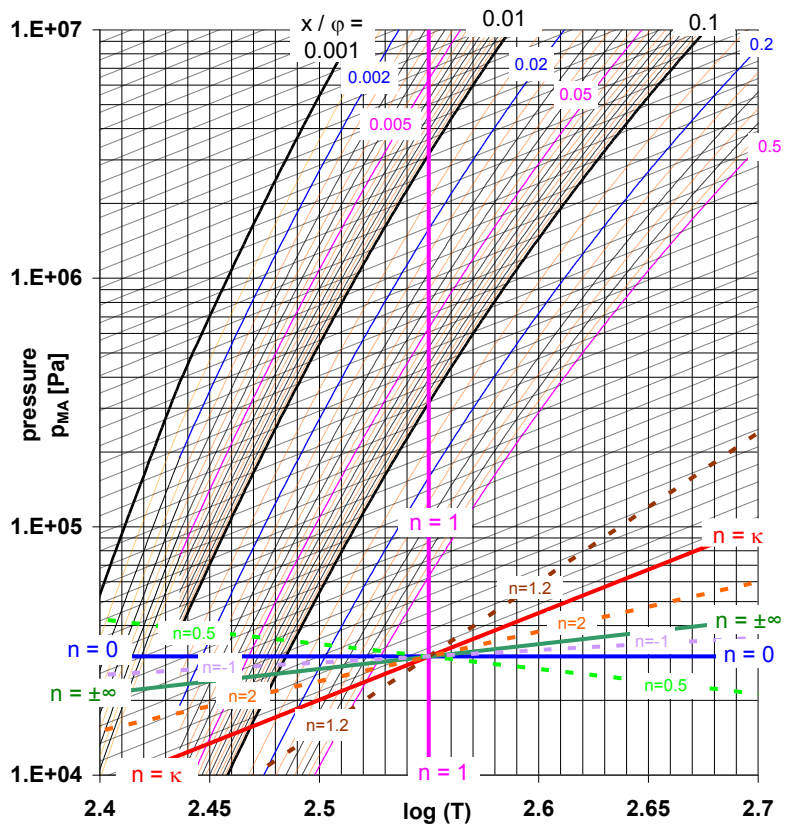

Fig. 6. The display polytrophic state changes in the moist air in a logarithmic $p$ - $T$ diagram.

Figure 6 shows the equilibrium diagram pressure $p[\mathrm{~Pa}]$ - the decimal logarithm of temperature $T[\mathrm{~K}]$. A standard logarithmic scale is used for the vertical axis (corresponding to pressure). The moist air temperature is in order of hundreds of Kelvin, so it is not possible to use a normal logarithmic scale: values on the horizontal axis thus correspond directly to the decimal logarithm of the temperature $\log (T)$. In the diagram is again drawn a curve set $x / \varphi=$ const . and a further set of curves $s=$ konst . (these curves form a set of lines with a slope $\operatorname{tg}(\alpha)=\frac{\kappa}{\kappa-1}$ in the logarithmic diagram). Additionally, at the bottom of the diagram is displayed directional rosette of polytrophic changes for basic changes and for some selected values of polytrophic exponent! In solving any general change of state in moist air, we will look for a final state on a line parallel to the line corresponding to the specified polytrophic exponent in the directional rosette, passing through the starting point (corresponding to the specified state: pressure, temperature and moisture).

\section{Relative uncertainty of the used approximation}

The relative uncertainty $\delta$ of such approximations when calculating the pressure of moist air (see 12) is equal to

$$
\delta=\frac{1}{0.622 \cdot \frac{1}{x}+1}
$$

and therefore depends only on the value of specific moisture:

- uncertainty $\delta<1 \%$ at specific moisture

$$
x<0.0063 \frac{\mathrm{kg}_{\mathrm{v}}}{\mathrm{kg}_{\mathrm{DA}}} \text {; }
$$

- uncertainty $\delta<2 \%$ at specific moisture

$$
x<0.0127 \frac{\mathrm{kg}_{\mathrm{v}}}{\mathrm{kg}_{\mathrm{DA}}} ;
$$

- uncertainty $\delta<5 \%$ at specific moisture $x<0.0327 \frac{\mathrm{kg}_{\mathrm{v}}}{\mathrm{kg}_{\mathrm{DA}}}$.

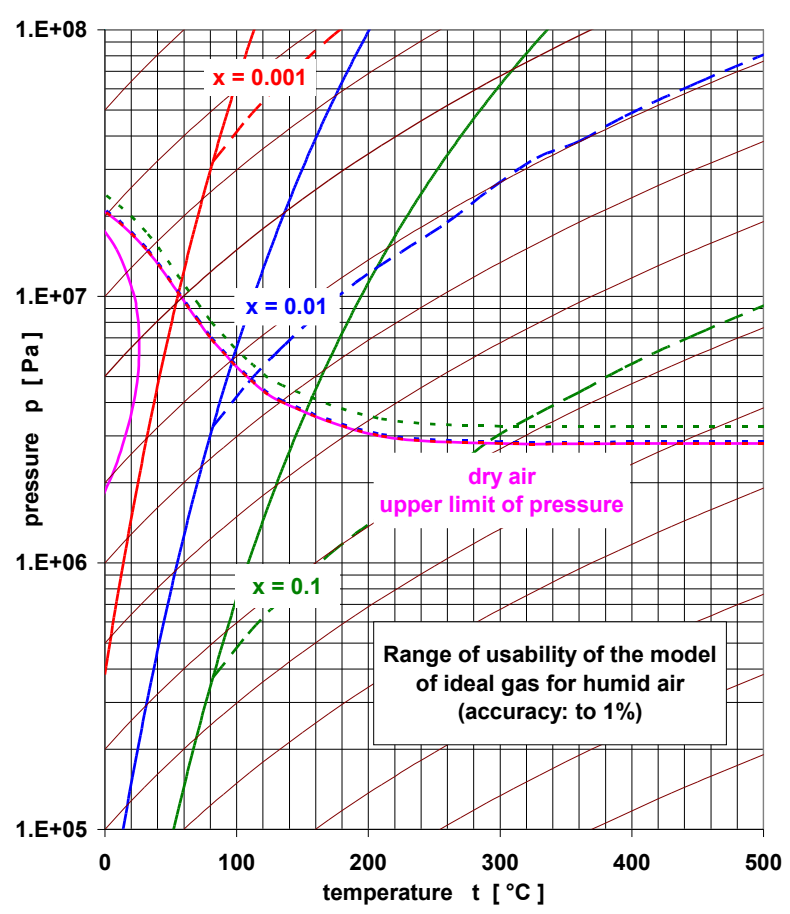

Fig. 7a. Area of usability of the ideal gas model for the calculation of properties of components of moist air at the required accuracy of the calculation to $1 \%$ for specific moisture $x$ of $0.1,0.01$ and $0.001\left[\mathrm{~kg}_{\mathrm{v}} / \mathrm{kg}_{\mathrm{DA}}\right]$ [6].

Therefore, if we insist on accuracy up to $1 \%$ when using our diagram, it is necessary to check both the value of the specific moisture $x$ (not to exceed $\left.x=0.0063 \mathrm{~kg}_{\mathrm{v}} / \mathrm{kg}_{\mathrm{MA}}\right)$ and the position of the point in the diagram - see Figure 7a [6]. If we insist on accuracy up to $2 \%$, it is necessary to check both the value of the specific moisture $x$ (not to exceed $x=0.0127 \mathrm{~kg}_{\mathrm{v}} / \mathrm{kg}_{\text {мA }}$ ) and the position of the point in the diagram - see Figure $7 \mathrm{~b}$ [6]. If it's enough for us the accuracy $5 \%$, it is necessary to check both the value of the specific moisture $x$ (not to exceed $x=0.0327 \mathrm{~kg}_{\mathrm{v}} / \mathrm{kg}_{\text {MA }}$ ) and the position of the point in the diagram - see Figure 7c [6]. 


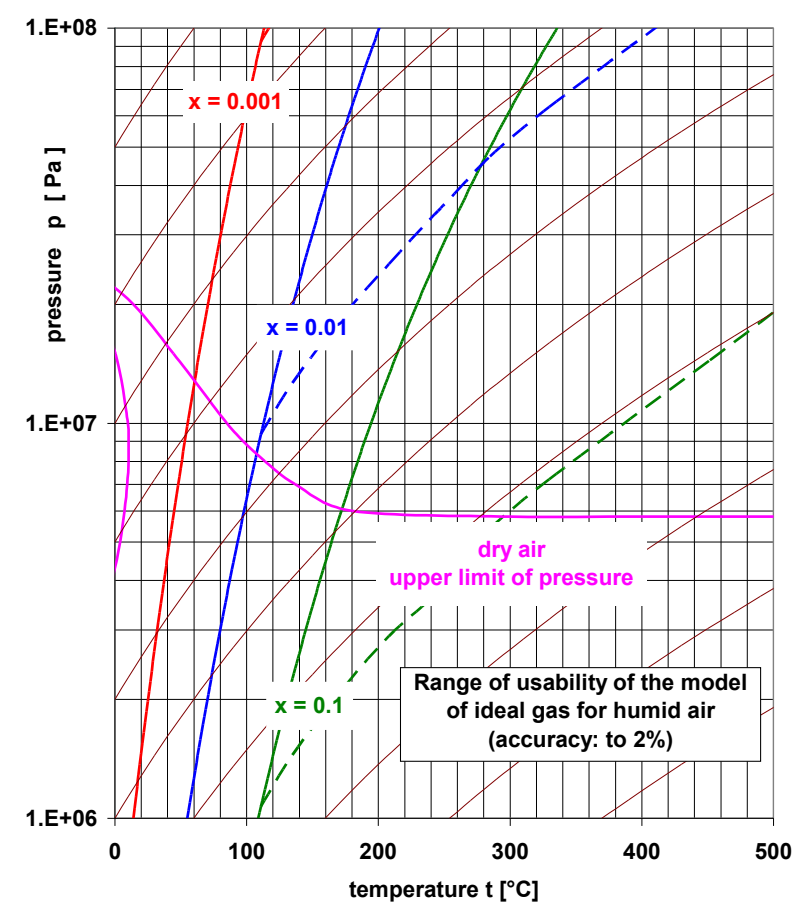

Fig. 7b. Area of usability of the ideal gas model for the calculation of properties of components of moist air at the required accuracy of the calculation to $2 \%$ for specific moisture $x$ of $0.1,0.01$ and $0.001\left[\mathrm{~kg}_{\mathrm{v}} / \mathrm{kg}_{\mathrm{DA}}\right]$ [6].

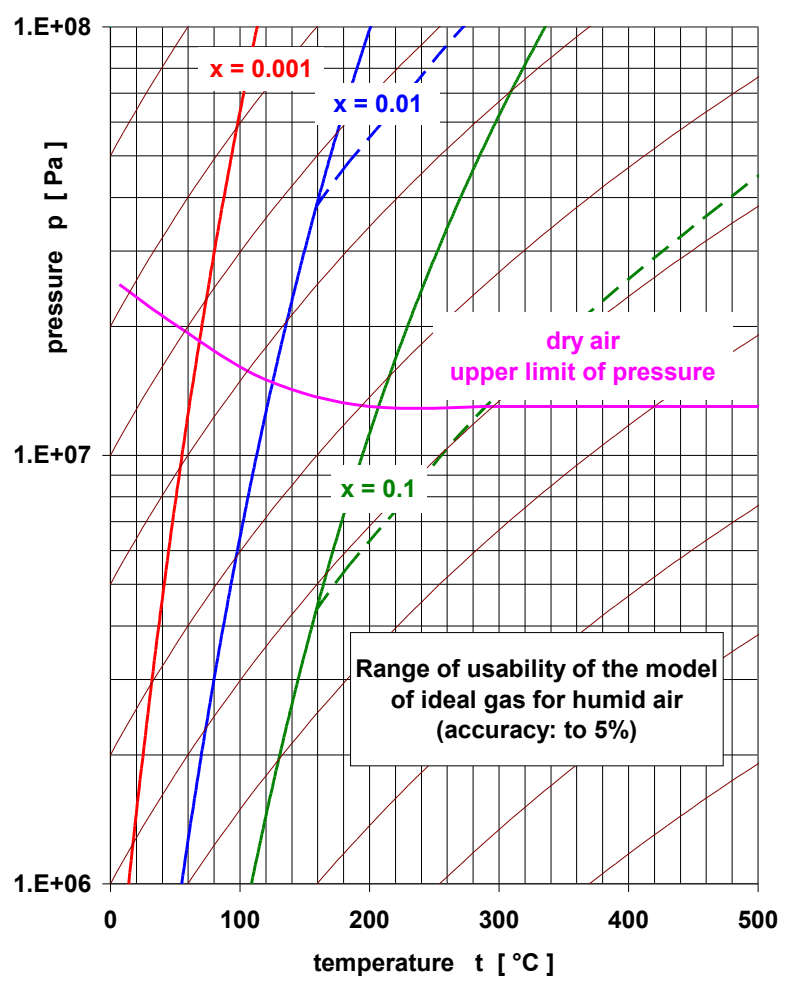

Fig. 7c. Area of usability of the ideal gas model for the calculation of properties of components of moist air at the required accuracy of the calculation to $5 \%$ for specific moisture $x$ of $0.1,0.01$ and $0.001\left[\mathrm{~kg}_{\mathrm{v}} / \mathrm{kg}_{\mathrm{DA}}\right][6]$.

\section{Conclusion}

Assuming the ideal behavior of gaseous components of moist air (dry air and water vapor), an equilibrium $p-t$ diagram was constructed with a set of curves of a constant ratio of specific and relative moisture, enabling to determine the state of moist air at different pressures and to solve even such thermodynamic processes occurring in moist air, where the pressure changes.

This publication was written at the Technical University of Liberec, Faculty of Mechanical Engineering with the support of the Institutional Endowment for the Long Term Conceptual Development of Research Institutes, as provided by the Ministry of Education, Youth and Sports of the Czech Republic in the year 2018.

The second author, P.Šafařik, expresses thanks for support from the Project No. CZ.2.16/3.100/21569 Centre 3D Volumetric Anemometry.

\section{References}

1. P. Šafařík, M. Vestfálová, Thermodynamics of Moist Air, CTU Publishing House (in Czech) (2016)

2. IAPWS Revised Release on the IAPWS Industrial Formulation 1997 for the Thermodynamic Properties of Water and Steam, Lucern (2007)

3. IAPWS: Revised Release on the Pressure along the Melting and Sublimation Curves of Ordinary Water Substance (2011)

4. M.Vestfálová, P.Šafařík, EPJ Web of Conferences, 143, 02139 (2017)

5. M.J. Moran, H.N.Shapiro, Fundamentals of Engineering Thermodynamics, John Wiley \& Sons, Inc., New York, (1992)

6. M. Vestfálová, P. Šafařík, EPJ Web of Conferences 180, 021115 (2018) 